\title{
Latencies on response-initiated fixed-interval schedules: Effects of signaling food availability
}

\author{
RICHARD L. SHULL, MARILYN GUILKEY, and PATRICK T. BROWN \\ University of North Carolina at Greensboro, Greensboro, North Carolina 27412
}

\begin{abstract}
Three pigeons were trained on a response-initiated fixed-interval schedule of food reinforcement where the first keypeck in the presence of one key color changed the key color and started a fixed time interval, after which a keypeck produced food. The latency to begin the fixedinterval component was an increasing function of the fixed-interval duration, which was either 40 or $80 \mathrm{sec}$. At both interval durations, a condition was also studied where the key color changed again at the end of the fixed interval, signaling the availability of food reinforcement. Adding the signal reduced the rate of keypecking during the fixed-interval component but did not systematically affect the initial latency to start the fixed-interval component.
\end{abstract}

Basic to several theories of reinforcement is the notion that behavior adjusts so as to maximize the parameters of reinforcement, such as rate (Baum, 1973; Logan, 1960; Rachlin, Green, Kagel, \& Battalio, 1976; Shimp, 1969; Treisman, 1975). This adjustment results from a shaping process: Variations in responding along some dimension are associated with variations along a dimension of reinforcement. The response value receiving the greatest net reinforcement is the one that should occur most often, and, to the extent that it does, the net reinforcement will be at a maximum. While much data are consistent with this maximization principle, the performance on response-initiated fixedinterval (FI) schedules appears, at least on the surface, inconsistent. On these schedules the first response after a fixed interval of time elapses (the FI) produces the reinforcer, but a response is also required after each reinforcement to start the next FI. Since a response starts the FI, the overall rate of reinforcement depends on how quickly the subject responds after the last reinforcement; any pausing before the initial response will reduce the overall rate of reinforcement below the maximum possible. It seems surprising, therefore, that subjects on response-initiated FI schedules usually wait for some time after reinforcement before making the response that starts the next FI (Mechner, Guevrekian, $\&$ Mechner, 1963). Further, the duration of this initial latency is an increasing function of the FI duration (Chung \& Neuringer, 1967; Shull, 1970; Shull \& Guilkey, 1976). The problem, then, is to explain why differences in the overall rate of reinforcement do not cause the latency to shorten to its minimum possible duration.

This research was supported by Grant BNS76-04317 from the National Science Foundation. We thank T. Bryson, G. Capehart, and S. McGee for helpful suggestions during the preparation of the paper. Reprints may be obtained from R. L. Shull, Department of Psychology, University of North Carolina at Greensboro, Greensboro, North Carolina 27412.
One possibility is that the subjects are simply not very sensitive to overall rates of reinforcement on these schedules. That is, overall reinforcement rate might not be an effective dimension of reinforcement. Instead, the major controlling dimension might be the amount of time from the end of the latency until the reinforcer, that is, the delay of reinforcement timed from the response that ends the latency. In a variety of situations, the tendency to initiate an activity is a decreasing function of this delay-of-reinforcement interval independently of the specific response during the interval (Ferster \& Hammer, 1965; Killeen, 1968; Neuringer, 1969; Pierce, Hanford, \& Zimmerman, 1972). The positive relation between the latency and the FI on response-initiated FI schedules might be another instance of a delay-of-reinforcement effect since the latency of a response is an increasing function of its delay of reinforcement (Azzi, Fix, Keller, \& Rocha e Silva, 1964; Keller, 1966; Logan, 1960; Morgan, 1972; Pierce et al., 1972).

There is an alternative possibility that is consistent with an overall reinforcement-rate maximization principle. The latency might reflect time spent engaging in activities of importance to the subject that are not directed toward obtaining the reinforcer scheduled at the end of the FI. Such activities might include resting, grooming, stretching, or simply avoidance of behavior directed toward the terminal reinforcer. Subjects probably have difficulty engaging in these interim activities at times when they are engaging in behavior directed toward the terminal reinforcer, or terminal behavior (Staddon, 1977; Staddon \& Simmelhag, 1971). Since terminal behavior tends to predominate once the response occurs that starts the FI, interim activities would be restricted mainly to the time before the initial response. Any reinforcement derived from interim activities, then, would tend to lengthen the latency, counteracting the effect of the overall rate of the scheduled reinforcer to shorten the latency. The latency 
that emerges would be a sort of balance point where the net reinforcement is greatest. If the "sufficient" time for interim activities is some proportion of the total time, the latency would be an increasing function of the FI duration on response-initiated FI schedules.

If the second possibility is correct, the latency should shorten if the amount of terminal behavior is somehow reduced in the period following the end of the latency. More time would then be available for interim behavior during that period, and so the latency could shorten without reducing the total amount of time devoted to interim activities. Reducing the amount of terminal behavior after the end of the latency might prove difficult, however. No doubt the amount of a previously required response could be reduced by eliminating the response requirement after the end of the FI for the terminal reinforcer. But this change would probably not reduce the total amount of terminal behavior because that amount seems to depend mainly on the relations between stimuli and the terminal reinforcer (Killeen, 1968; Staddon \& Simmelhag, 1971). These stimulus relations would be about the same whether or not a specific response was required after the end of the FI. Put another way, if the elimination of the response requirement after the end of the FI reduces the amount of the previously required response, some other terminal response-for example, remaining in readiness for the terminal reinforcer (Mowrer, 1940)-probably increases in a compensatory way.

A more promising way to reduce the amount of terminal behavior during the FI might be to add an "exteroceptive clock" to the FI; that is, an exteroceptive stimulus change at the end of the FI to signal reinforcer availability (Ferster \& Skinner, 1957; Segal, 1962). The stimulus conditions during the FI should, then, become a signal for the nonavailability of the terminal reinforcer, and terminal behavior might decrease as a result (Staddon \& Simmelhag, 1971). Speaking loosely, there would be no need to remain ready for the terminal reinforcer during the FI if an external stimulus change cued the end of the interval. In the present study, the effects of signaling food availability at the end of the FI were studied with response-initiated FI schedules. The aim was to see whether the latency would decrease as a result of adding an exteroceptive clock.

\section{METHOD}

\section{Subjects}

The subjects were three adult male domestic pigeons maintained at about $80 \%$ of their free-feeding weights. They had had extensive prior experience with fixed-ratio and variableinterval schedules of food reinforcement.

\section{Apparatus}

A sound-attenuating shell enclosed the experimental cubicle measuring $31 \times 37 \times 36 \mathrm{~cm}$. White noise in the chamber and a ventilating fan helped mask extraneous noises. One wall of the chamber contained a rectangular opening for presenting mixed grain, centered $10 \mathrm{~cm}$ above the floor. To the right of the feeder opening, $25 \mathrm{~cm}$ above the floor, was a $2.5-\mathrm{cm}$-diam translucent response key that required a minimum of $.2 \mathrm{~N}$ to operate. Key closures of sufficient force produced a brief click from a relay mounted behind the key and also operated appropriate control and recording circuits constructed of standard electromechanical equipment. The key could be transilluminated with different colored lights. A lamp (GE 1829) centered near the top of the front wall provided low-level general illumination.

The reinforcer consisted of 4-sec access to mixed grain, during which the response key and the houselight were darkened and the feeder opening was illuminated.

\section{Procedure}

Because of their extensive previous training, no special pretraining was needed. This study compared the effects of having or not having a stimulus change at the end of a responseinitiated FI schedule (an external "clock") under two different values of the FI.

The "no-clock" condition was a chain FR-1/FI schedule. That is, the key was white at the start of the session and after each food delivery. The first keypeck in white changed the key color to red and started a time interval (the FI). The first keypeck after the end of the FI produced grain, after which white was reinstated. Keypecks during the FI had no effect on the delivery of food.

The "clock" condition was identical except that the key light changed from red to green at the end of the FI, signaling that the next keypeck would produce grain. In addition, a requirement was added to quickly reduce keypecking in red. Any pecks during the last quarter of the FI, while the key was red, stopped the timing of the FI for $2 \mathrm{sec}$. This insured that the occurrence of green, and the availability of food, could not occur within 2 sec of a keypeck in red.

With the FI set at $40 \mathrm{sec}$, first the clock and then the noclock conditions were studied for 32 and 15 sessions, respectively. Next the FI was increased to $80 \mathrm{sec}$ and the noclock, clock, and no-clock conditions were studied for 16,16 , and 17 sessions, respectively. Bird M2 was studied on the 80-sec clock condition a second time for 14 sessions because very long pauses occasionally occurred during the first determination of that condition.

Sessions were conducted daily and contained 50 food deliveries. The chamber was darkened before the start of the session and after the 50th food delivery.

\section{RESULTS}

The major finding was that the duration of the latency to start the FI varied directly with the duration of the FI and was fairly independent of the presence or absence of the stimulus change at the end of the FI. In contrast, the rate of keypecking during the FI varied mainly with the presence or absence of the clock. Figure 1 shows sample cumulative records that illustrate these effects.

Mean data derived from the last five sessions of each condition provide additional confirmation. Figure 2 shows for all birds the mean latency to start the FI and the mean response rate during the $\mathrm{FI}$; that is, the number of keypecks excluding the first (the FR 1) and the last (the one that produced food) divided by the accumulated time during the timing of the FI. Figure 2 also shows the keypecking rate in successive fourths of the FI, in order to reveal the control by elapsed time 

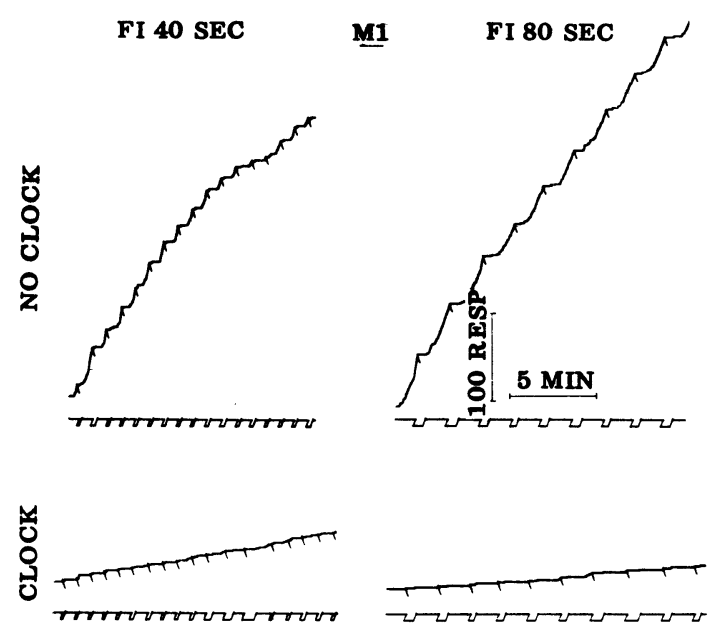

Figure 1. Sample cumulative records (cumulative keypecks plotted over elapsed time) from the last session of each condition for Bird M1. The event pen deflected down during the latency to start the FI. The diagonal slash marks on the response curve indicate food deliveries.

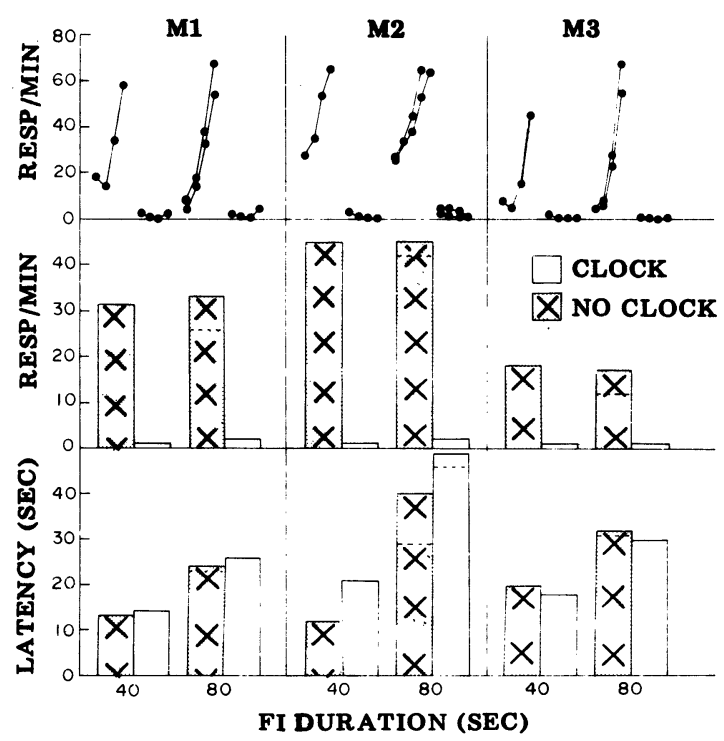

Figure 2. The latency to start the FI (bottom panel), the mean response rate during the FI (middle panel), and the mean response rate in each quarter of the FI for each condition (top panel). Means are derived from the last five sessions of a condition. The horizontal dashed lines on the bars show the lower value of two determinations of a condition; initial and redetermination data are not differentiated in the top panels. Each column shows data from a different bird. The duration of the FI is indicated at the bottom.

since the start of the FI. While the rate and patterning of keypecking depended mainly on the presence or absence of the clock, the mean latency to start the FI depended mainly on the duration of the FI. For Bird M2 latencies were longer with than without the clock at both FI durations. However, the changes in latency due to the addition of the clock were small for the other two birds and inconsistent in direction. For all birds, the addition of the clock reduced keypecking rates during the FI and eliminated evidence of temporal control over keypecking.

Figure 3 shows transition data: The mean latency to start the FI and the mean response rate during the FI are shown for the five sessions immediately preceding and immediately following a change in the clock condition at the 80-sec FI duration. Even though the response rate was changing rapidly over the first few sessions following the condition change, the independence of the latency and response rate was still apparent.

\section{DISCUSSION}

The independence of the latency from the presence or absence of the clock is consistent with data from other procedures showing that the latency to initiate a terminal link of a chain schedule is relatively insensitive to the amount of measured terminal behavior in the terminal link (Ferster \& Hammer, 1965). This independence can be interpreted two ways. One could accept that the exteroceptive clock reduced the amount of terminal behavior during the FI and conclude that the latency depends mainly on the time to reinforcement after the end of the latency, or one could view the invariance

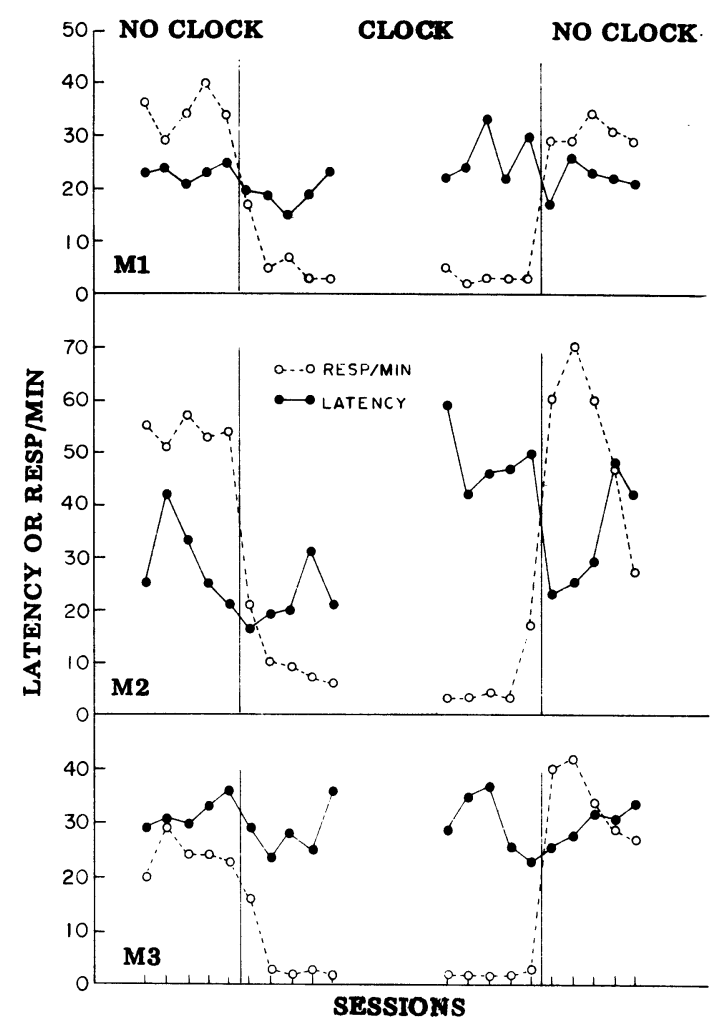

Figure 3. The mean latency to start the FI and the mean response rate during the FI plotted over successive sessions of the conditions indicated. The FI was 80 sec. 
in the latency as presumptive evidence that the clock did not alter the "true" amount of terminal behavior.

Independent of these issues, the present data correspond well with the results of similar manipulations using choice procedures. Schrader and Rachlin (1976), for example, found that the preference between two fixed-interval or two variableinterval schedules depended on the durations of the schedules independently of whether an exteroceptive clock was added to one of the schedules. Thus, the data are consistent with the idea that postreinforcement latency and choice measures are sensitive to the same variables.

\section{REFERENCES}

Azzi, R., Fix, D. S. R., Keller, F. S., \& Rocha e Silva, M. I. Exteroceptive control of a response under delayed reinforcement. Journal of the Experimental Analysis of Behavior, 1964, 7, 159-162.

BAUM, W. M. The correlation-based law of effect. Journal of the Experimental Analysis of Behavior, 1973, 20, 137-153.

Chung, S.-H., \& Neuringer, A. J. Control of responding by a percentage reinforcement schedule. Psychonomic Science, $1967,8,25-26$.

Ferster, C. B., \& Hammer, C. Variables determining the effects of delay in reinforcement. Journal of the Experimental Analysis of Behavior, 1965, 8, 243-254.

Ferster, C. B., \& SKInNER, B. F. Schedules of reinforcement. New York: Appleton-Century-Crofts, 1957.

Keller, J. V. Delayed escape from light by the albino rat. Journal of the Experimental Analysis of Behavior, 1966, 9, 655-658.

Killeen, P. Response rate as a factor in choice. Psychonomic Science, 1968, 12, 34.

LoGAN, F. A. Incentive: How the conditions of reinforcement affect the performance of rats. New Haven: Yale University Press, 1960.

Mechner, F., Guevrekian, L., \& Mechner, V. A fixed interval schedule in which the interval is initiated by a response. Journal of the Experimental Analysis of Behavior, 1963, 6, 323-330.

Morgan, M. J. Fixed-ratio performance under conditions of delayed reinforcement. Journal of the Experimental Analysis of Behavior, 1972, 17, 95-98.

Mowrer, O. H. Preparatory set (expectancy)-Some methods of measurement. Psychological Monographs, 1940, 52, 1-43.

NeURINGER, A. J. Delayed reinforcement versus reinforcement after a fixed interval. Journal of the Experimental Analysis of Behavior, 1969, 12, 375-383.

Pierce, C. H., Hanford, P. V., \& Zimmerman, J. Effects of different delay of reinforcement procedures on variableinterval responding. Journal of the Experimental Analysis of Behavior, 1972, 18, 141-146.

Rachlin, H., Green, L., Kagel, J. H., \& Battalio, R. C. Economic demand theory and psychological studies of choice. In G. H. Bower (Ed.), The psychology of learning and motivation: Advances in research and theory (Vol. 10). New York: Academic Press, 1976. Pp. 129-154.

Schrader, S. M., \& Rachlin, H. Variable-interval and fixed-interval schedule preferences in pigeons as a function of signaled reinforcement and schedule length. Bulletin of the Psychonomic Society, 1976, 8, 445-448.

SEGAL, E. F. Exteroceptive control of fixed-interval responding. Journal of the Experimental Analysis of Behavior, 1962, 5, 49-57.

Shimp, C. P. Optimal behavior in free-operant experiments. Psychological Review, 1969, 76, 97-112.

SHulL, R. L. A response-initiated fixed-interval schedule of reinforcement. Journal of the Experimental Analysis of Behavior, 1970, 13, 13-15.

Shull, R. L., \& GuILKey, M. Food deliveries during the pause on fixed-interval schedules. Journal of the Experimental Analysis of Behavior, 1976, 26, 415-423.

Staddon, J. E. R. Induced behavior. In W. K. Honig \& J. E. R. Staddon (Eds.), Handbook of operant behavior. Englewood Cliffs, N.J: Prentice-Hall, 1977.

Staddon, J. E. R., \& Simmelhag, V. L. The "superstition" experiment: A re-examination of its implications for the principles of adaptive behavior. Psychological Review, 1971, 78, 3-43.

Treisman, M. Predation and the evolution of gregariousness. I. Models for concealment and evasion. Animal Behaviour, 1975, 23, 779-800.

(Received for publication June 6, 1978.) 